\title{
Revealing past ocean circulation with neodymium isotopes
}

Patrick Blaser ${ }^{1}$, M. Frank ${ }^{2}$ and T. van de Flierdt ${ }^{3}$

\begin{abstract}
The dissolved neodymium isotope composition of seawater is widely used to study past changes in provenance and mixing of different water masses in the ocean. We discuss mechanisms controlling signal formation and preservation, proxy strengths, and current challenges.
\end{abstract}

The samarium-neodymium ( $\mathrm{Nd}$ ) decay system has been widely used to determine the age of crustal rocks and the provenance of detrital sediments. However, the dissolved radiogenic isotope composition of $\mathrm{Nd}$ (expressed as $\left.\varepsilon_{\mathrm{Nd}}=\left[\left({ }^{143} \mathrm{Nd} /{ }^{144} \mathrm{Nd}\right) / 0.512638-1\right] \times 10^{4}\right)$ in seawater also traces the distribution of major water masses and their mixing. This is the foundation for using $\mathrm{Nd}$ isotopes as a tracer for ocean circulation (van de Flierdt et al. 2016).

\section{Disentangling ocean circulation from carbon storage}

For decades, the reconstruction of past ocean circulation relied on the stable isotope composition of the nutrient com ponent carbon (C) in marine calcareous organisms $\left({ }^{13} \mathrm{C} /{ }^{12} \mathrm{C}\right.$ ratio expressed as $\delta{ }^{13} \mathrm{C}$; Fig. 1). However, both biological cycling and ocean circulation play major roles in setting the measured $\delta^{13} \mathrm{C}$ signature. In contrast, the lithogenic element $\mathrm{Nd}$ is not actively involved in marine biological cycling. Recorded in and extracted from oceanic archives, radiogenic $\mathrm{Nd}$ isotopes fingerprint where a water mass acquired its $\mathrm{Nd}$ isotope signature. Thus, the combination of $\mathrm{Nd}$ and $C$ isotopes in oceanic archives allows us to disentangle deep ocean circulation from carbon storage under past climatic conditions and becomes more valuable than the sum of its parts.
For example, Piotrowski et al. (2005) combined $\mathrm{Nd}$, oxygen, and carbon isotopes from a high sedimentation site in the South Atlantic to show that glacial-interglacial transitions first manifested themselves in changes in ice sheets, followed by ocean carbon storage, and finally ocean circulation. Pena and Goldstein (2014) extended the $\varepsilon_{\mathrm{Nd}}$ record across the mid Pleistocene and found that Atlantic meridional overturning skipped a beat during interglacial marine isotope stage 23 (approximately $900 \mathrm{kyr} \mathrm{BP),}$ increasing carbon sequestration and thereby promoting ice-sheet build-up and setting the stage for the mid-Pleistocene transition. During this period, glacial cycles switched from a 41 kyr periodicity to one of $100 \mathrm{kyr}$ (see also Farmer et al. this issue). For the Last Glacial Maximum, Howe et al. (2016a) compiled Atlantic $\varepsilon_{\mathrm{Nd}}$ data suggesting that southern sourced water was less prevalent than inferred from carbon isotopes. This implies that biological cycling must have played a greater role than previously thought. These examples demonstrate the value of seawater derived $\varepsilon_{\mathrm{Nd}}$ as a water-mass proxy in the paleoceanographer's toolbox.

\section{What determines the seawater} Nd isotope signal?

Lithogenic in origin, dissolved $\mathrm{Nd}$ is introduced into surface waters by erosion and weathering of continental crust. Hence, water masses typically acquire their $\mathrm{Nd}$ isotope fingerprint at the interface with continents. Subsequently, convection leads to the export of these characteristic $\varepsilon_{\mathrm{Nd}}$ signatures to deep waters (Fig. 1).

The mean residence time of $\mathrm{Nd}$ in the deep oceans is on the order of centuries, and is thus similar to the mean ocean overturning time. This similarity of time constants is the decisive factor rendering $\varepsilon_{\mathrm{Nd}}$ a suitable tracer for ocean water masses. Hence, $\varepsilon_{\mathrm{Nd}}$ behaves largely conservatively away from ocean margins (no significant sources or sinks), with measured signatures primarily reflecting the mixture of distinct water masses transported across ocean basins (Fig. 2a). On regional and local scales, however, geochemical processes can modulate the residence time of $\mathrm{Nd}$ dissolved in seawater.

The concentration of dissolved Nd generally increases with water depth, indicating a combined control of advection and vertical transport via adsorption and desorption from particles. This can transfer Nd vertically through the water column and across watermass boundaries. At the ocean bottom, fluxes of $\mathrm{Nd}$ across the sediment-seawater interface have been observed both into and out of bottom waters (Haley et al. 2017). In general, such benthic exchange depends on the reactivity of detrital material releasing $\mathrm{Nd}$ in the sediment. Exchange may also be facilitated within benthic nepheloid layers

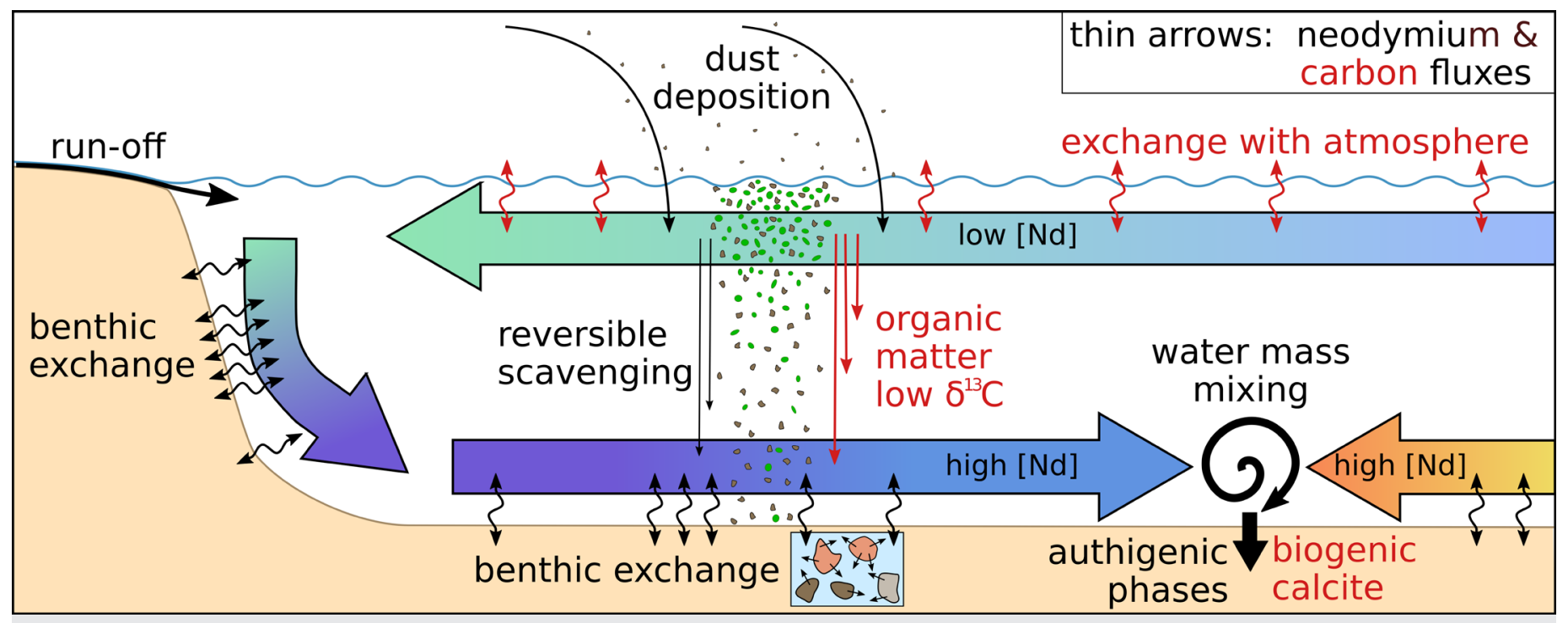

Figure 1: Simplified scheme of the most relevant biogeochemical processes influencing Nd and C isotope compositions of water masses; from surface water via deep endmember formation to mixing and archiving. Large arrows represent water masses with colors qualitatively implying different isotope compositions. 
a) Modern observations

b) Deglacial evolution

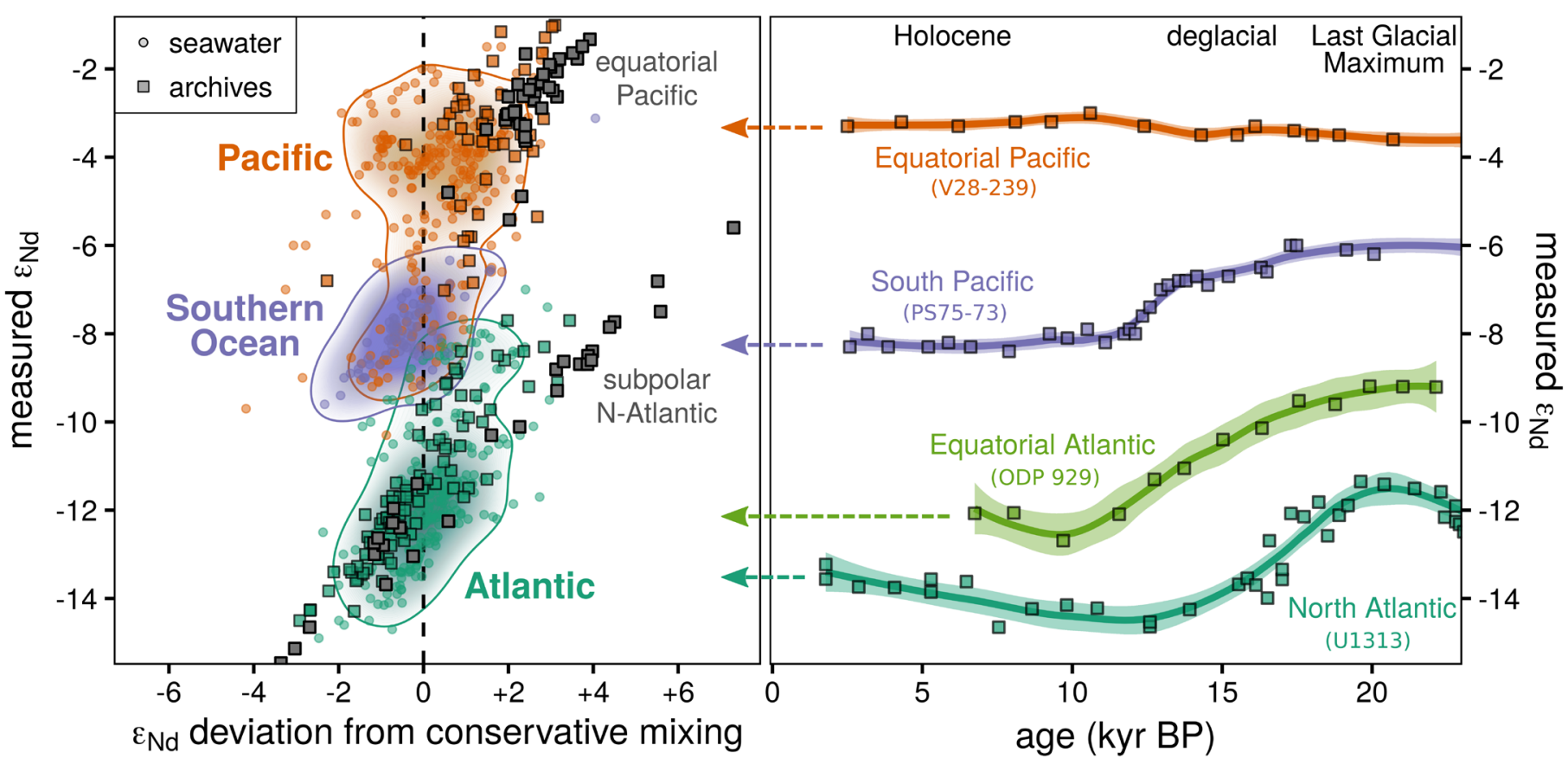

Figure 2: (A) Measured $\varepsilon_{\mathrm{Nd}}$ of seawater and "young" archives (>1500m depth) vs. their deviation from purely conservative mixing of water-mass end-members (Tachikawa et al. 2017). Pacific $\varepsilon_{\mathrm{Nd}}$ values are high due to ubiquitous young volcanic rocks, whereas old terranes around the North Atlantic lead to low $\varepsilon_{\mathrm{Nd}}$. The Southern (and Indian) Ocean exhibits intermediate signatures. (B) The $\varepsilon_{\text {Nd }}$ evolution from four representative deep sites since the Last Glacial Maximum (Basak et al. 2018; Howe et al. 2016b; Hu and Piotrowski 2018; Lippold et al. 2016; Pöppelmeier et al. 2018). Higher glacial $\varepsilon_{\mathrm{Nd}}$ in the Atlantic is generally interpreted to indicate the presence of more Pacific-sourced water, but uncertainties in past end-member $\varepsilon_{\mathrm{Nd}}$ and $\mathrm{Nd}$ concentrations complicate such interpretations.

through the availability of large particle surface areas (van de Flierdt et al. 2016).

Geochemical processes are not necessarily restricted to regions where water masses are formed and their end-member characteristics are defined. Therefore, a non-conservative element is added to the distribution of $\varepsilon_{\mathrm{Nd}}$ in seawater. Ultimately, it is the balance of physical water-mass advection (conservative component) and geochemical processes (non-conservative component) that determines the residence time of dissolved $\mathrm{Nd}$ in seawater and whether its isotope composition primarily reflects water-mass mixing. In environments in which exchange processes lead to faster replacement of $\mathrm{Nd}$ than watermass transit, $\varepsilon_{\mathrm{Nd}}$ may even be applicable as a kinematic proxy, as Du et al. (2018) suggested for the North Pacific.

\section{What do the archives tell us?}

Marine archives record the local $\mathrm{Nd}$ isotope signatures of water-mass mixtures. The extraction of unaltered past seawater $\varepsilon_{\mathrm{Nd}}$ is challenging but has been achieved from fossil fish debris, deep-sea coral skeletons, and ferromanganese deposits in the form of crusts, nodules, and coatings on bulk sediment particles and inside foraminiferal calcite tests (Fig. 2a).

However, the early diagenetic archiving process is currently not well understood and in some regions all attempts to extract local bottom water $\varepsilon_{\mathrm{Nd}}$ from core-top sediments have failed (see gray indicated regions in Fig. 2a). The archiving processes comprise co-precipitation of $\mathrm{Nd}$ with iron-manganese oxyhydroxides, diffusion into biogenic apatite, and the precipitation in microbially mediated microenvironments. Hence, for sedimentary $\varepsilon_{\mathrm{Nd}}$ signatures, one possible explanation for discrepancies compared to seawater $\varepsilon_{\mathrm{Nd}}$ is that a pore-water signal is recorded, which itself can reflect a mixture of bottom water and detrital $\varepsilon_{\mathrm{Nd}}$. Pore waters and sedimentary authigenic phases could thus carry additional information about the strength of past benthic exchange (Du et al. 2016).

\section{Improving Nd isotope-based} reconstructions of water masses

Mechanisms and magnitudes of Nd supply to the oceans via particles, reactive sediments, or in dissolved form can vary as a function of climatically controlled parameters such as precipitation or ice and vegetation cover on the continents. Thus, the accuracy of $\varepsilon_{\mathrm{Nd}}$ as a paleo water-mass proxy often depends on the knowledge of past end-member characteristics (Fig. 2b; Howe et al. 2016a; Pöppelmeier et al. 2018), the impact of non-conservative processes (Blaser et al. 2019), and the fidelity of the archive and extraction method used (Blaser et al. 2016; Du et al. 2016).

Paleoceanographic reconstructions from settings with little input of reactive detritus and expected large water mass fluxes will be least affected by such uncertainties, and interpretations will ideally be based on $\varepsilon_{N d}$ gradients between different sites. Better data coverage within and near regions of significant benthic exchange and end-member formation, as well as incorporation of $\mathrm{Nd}$ concentrations and $\varepsilon_{\mathrm{Nd}}$ in ocean circulation models will be important steps to gain deeper insights into past oceanic Nd cycling and water mass circulation. The combination of several tracers can eliminate uncertainties of individual proxies. At the same time a better understanding of present-day $\mathrm{Nd}$ cycling through measurements along ocean sections and dedicated process studies at key locations, currently performed as part of the international GEOTRACES program (geotraces.org), will increase the reliability of interpretations based on Nd isotopes.

\section{AFFILIATIONS}

'Institute of Earth Sciences, Heidelberg University, Germany

${ }^{2}$ GEOMAR Helmholtz Centre for Ocean Research Kiel, Germany

${ }^{3}$ Department of Earth Science and Engineering, Imperial College London, UK

\section{CONTACT}

Patrick Blaser: patrick.blaser@geow.uni-heidelberg.de REFERENCES

Basak C et al. (2018) Science 359: 900-904 Blaser P et al. (2016) Chem Geol 439: 189:204 Blaser P et al. (2019) Geochim Cosmochim Acta 245: 79-97

Du J et al. (2016) Geochim Cosmochim Acta 193: 14-35 Du J et al. (2018) Nat Geosci 11: 749-755

Haley BA et al. (2017) Front Mar Sci 4: 426

Howe JNW et al. (2016a) Nat Commun 7: 11765 Howe JNW et al. (2016b) Geology 44: 831-834 Hu R, Piotrowski AM (2018) Nat Commun 9: 4709 Lippold J et al. (2016) Earth Planet Sc Lett 445: 68-78 Pena LD, Goldstein SL (2014) Science 345: 318-322 Piotrowski AM et al. (2005) Science 307: 1933-1938 Pöppelmeier F et al. (2018) Paleoceanogr Paleocl 33: 530-543

Tachikawa K et al. (2017) Chem Geol 457: 131-148 van de Flierdt T et al. (2016) Philos T R Soc A 374: 20150293 